\title{
Clinical Profile and Prognostic Significance of Atrial Fibrillation in Hypertrophic Cardiomyopathy
}

\author{
Tao Tian $^{a}$ Yilu Wang $^{\mathrm{a}}$ Kai Sun ${ }^{\mathrm{b}}$ Jizheng Wang ${ }^{\mathrm{b}}$ Yubao Zou ${ }^{\mathrm{a}}$ Weili Zhang $^{\mathrm{b}}$ \\ Jingru Bao ${ }^{c}$ Ling Zhu ${ }^{e}$ Hu Shen ${ }^{e}$ Rutai Hui ${ }^{a, b, d}$ Xianliang Zhou ${ }^{a, d}$ Lei Song ${ }^{a, d}$ \\ a Department of Cardiology, ${ }^{b}$ Sino-German Laboratory for Molecular Medicine, ${ }^{\mathrm{c} C l i n i c a l}$ EP Laboratory and Arrhythmia \\ Center and ${ }^{\mathrm{d}}$ Hypertension Center, State Key Laboratory of Cardiovascular Disease, Fuwai Hospital, National Center \\ for Cardiovascular Disease, Chinese Academy of Medical Sciences and Peking Union Medical College, Beijing, and \\ eDepartment of Cardiology, First Affiliated Hospital of Medical College, Xi'an Jiaotong University, Xi'an, China
}

\section{Key Words}

Hypertrophic cardiomyopathy · Atrial fibrillation · Prognosis

\begin{abstract}
Objectives: The clinical outcomes of hypertrophic cardiomyopathy (HCM) are largely unpredictable. This study aimed to investigate the relationship between atrial fibrillation (AF) and its prognostic implications in Chinese patients with HCM. Methods: From 1999 to 2011, 654 unrelated HCM patients were consecutively recruited at Fuwai Hospital. Medical history, including electrocardiographic and echocardiographic data, was analyzed. Results: AF was documented in 158 patients (24\%). During follow-up of $4.2 \pm 2.8$ years, Kaplan-Meier analysis revealed that the presence of AF was associated with an increased risk for all-cause death $(p=0.001)$, cardiovascular death $(p<0.001)$, severe heart failure $(p<$ $0.001)$ and ischemic stroke $(p<0.001)$. Multivariate analysis identified $\mathrm{AF}$ as an independent predictor of stroke-related death (HR 6.71, 95\% Cl 1.23-38.58, $\mathrm{p}=0.03$ ), advanced heart failure (HR 1.83, 95\% Cl 1.04-3.22, $\mathrm{p}=0.04)$ and ischemic stroke (HR 9.98, 95\% Cl 4.06-24.53, $\mathrm{p}<0.001)$. Furthermore, enlarged left atrial diameter was positively related to allcause death (HR 1.09, 95\% Cl 1.05-1.13, p < 0.001), cardiovascular death (HR 1.08, 95\% Cl 1.04-1.20, $\mathrm{p}<0.001)$ and
\end{abstract}

\section{KARGER}

E-Mail karger@karger.com

www.karger.com/crd development of advanced heart failure (HR 1.05, 95\% Cl 1.01-1.10, $p=0.01$ ). Conclusions: AF predicts poor outcomes for patients with HCM. Left atrial dilation is also related to an adverse prognosis and provides additional prognostic information.

(c) 2013 S. Karger AG, Basel

\section{Introduction}

Hypertrophic cardiomyopathy (HCM) is one of the most common inherited cardiac disorders, with marked heterogeneity in clinical manifestations and outcomes [1, 2]. Although HCM generally has a relatively benign prognosis in an unselected population $[3,4]$, some patients suffer from end-stage heart failure, stroke or premature sudden cardiac death (SCD) [5-7]. Consequently, identification of patients at high risk has great clinical significance for initiating early prevention and improving the prognosis of HCM. At present, some risk factors associated with SCD in HCM patients have been established [8]. A risk-stratification algorithm based on these factors is

Lei Song, $\mathrm{MD}, \mathrm{PhD}$

Fuwai Hospital, Chinese Academy of Medical Sciences (CAMS) \& Peking Union Medical College (PUMC)

167 Beilishi Road, Beijing 100037 (China)

E-Mail lsongqd@yahoo.com

Xianliang Zhou, MD, PhD

Hypertension Center, Fuwai Hospital

Chinese Academy of Medical Sciences (CAMS) \& Peking Union Medical College (PUMC), 167 Beilishi Road, Beijing 100037 (China)

E-Mail zhouxianliang0326@hotmail.com 
useful in identifying high-risk subjects for lifesaving intervention with an implanted cardioverter-defibrillator (ICD). However, risk factors related to heart failure and stroke in HCM patients are not well developed.

Atrial fibrillation (AF) is reported to occur in approximately $1 \%$ of the general population [9], but $20-30 \%$ of the $\mathrm{HCM}$ population $[4,10-13]$. Some studies suggest that AF is associated with adverse outcomes in patients with HCM and other cardiovascular diseases $[11,14,15]$. However, no prospective data have been reported in the Chinese HCM population. This study was therefore undertaken to investigate the prognostic value of AF in Chinese HCM patients.

\section{Methods}

\section{Population}

A total of 654 unrelated patients with HCM were consecutively recruited at Beijing Fuwai Hospital, Chinese Academy of Medical Sciences, from 1999 to 2011. All of the patients gave informed consent to participate in this research project, which was approved by the ethics committee of Fuwai Hospital. The diagnosis of HCM was based on a hypertrophied left ventricle with wall thickness $\geq 15$ $\mathrm{mm}$ (or $\geq 13 \mathrm{~mm}$ with an HCM family history) on echocardiography (or echocardiography and cardiac magnetic resonance imaging) in the absence of other cardiac or systemic diseases responsible for the hypertrophy (e.g. cardiac valve disease, uncontrolled hypertension or congenital heart disease) $[8,16]$. AF was documented based on ECG recordings obtained when patients presented with acute onset of symptoms or during routine examination on admission or based on 24-hour Holter monitoring. Three cardiologists independently reviewed all clinical data.

\section{Follow-Up}

The primary end points were all-cause death and cardiovascular death (including SCD, heart failure-related death and stroke-related death). SCD was defined as sudden, unexpected natural death from a cardiac cause occurring within 1 hour after the onset of symptoms in a person without any prior fatal condition. Potentially lethal cardiovascular events in which patients were either successfully resuscitated from cardiac arrest or received appropriate defibrillation from an implanted ICD were regarded as equivalent to SCD. Heart failure-related death was defined as death occurring in the context of long-term cardiac decompensation with progression of disease over the preceding year. Stroke-related death was defined as death occurring in patients who died of ischemic or hemorrhagic stroke.

The other end points included development of advanced chronic heart failure [New York Heart Association (NYHA) functional class deterioration from I/II to III/IV] or ischemic stroke. Chronic heart failure was diagnosed according to typical shortness of breath at rest or during exertion and/or fatigue, signs of fluid retention such as ankle swelling and objective evidence of an abnormality of the structure or function of the heart at rest [17].

Follow-up duration was calculated from the initial evaluation for patients with $\mathrm{AF}$ at enrollment, and from the time of onset of AF for patients with sinus rhythm at enrollment who developed AF during follow-up.

Significance of AF in Hypertrophic Cardiomyopathy
Statistical Analysis

Statistical analysis was performed with SPSS version 18.0 software (SPSS Inc., Chicago, Ill., USA). All data were expressed as mean \pm standard deviation or frequency. Differences in continuous variables were assessed using the Student t test, and the Wilcoxon rank-sum test was used when the distributions were asymmetric. The $\chi^{2}$ test was used for comparisons between noncontinuous variables, and if the patient number in any group was $<5$, the Fisher exact test was used. The Kaplan-Meier method was used to calculate survival time free from the end point events. A logrank test was used to compare survival curves among different patient groups. The Cox proportional hazard regression model was performed to identify variables associated with the end points. All statistical tests were two-sided and a $\mathrm{p}$ value of $<0.05$ was considered to be statistically significant.

\section{Results}

\section{Baseline Clinical Characteristics}

Of the 654 patients with HCM at enrollment, 112 (17\%) had AF. Of these, 86 (77\%) were identified during acute onset of symptoms, $19(17 \%)$ during routine examination on admission and 7 (6\%) during electrocardiography with Holter monitoring. Patients with AF were older (56 \pm 15 vs. $49 \pm 14$ years, $\mathrm{p}<0.001$ ) and had more severe heart failure (NYHA functional class III/IV, 21 vs. $10 \%, \mathrm{p}<0.001)$ than patients with sinus rhythm. Echocardiographic findings showed that patients with AF had a more dilated left atrium ( $45 \pm 8$ vs. $39 \pm 6 \mathrm{~mm}$ in diameter, $\mathrm{p}<0.001)$ and larger left ventricular (LV) end-diastolic diameter ( $46 \pm 6$ vs. $45 \pm 7 \mathrm{~mm}, \mathrm{p}=0.02$ ) (table 1 ).

\section{Clinical Outcomes}

New development of AF was identified in 46 patients during follow-up. Of these patients, 37 (80\%) were identified because of symptom onset, 7 (15\%) during routine medical examinations and 2 (4\%) during Holter monitoring. Overall, AF was documented in 158 (24\%) patients throughout the study. New occurrence of AF was independently predicted by aging (HR 1.04, 95\% CI 1.02-1.07, $\mathrm{p}=0.001$ ), severe heart failure (HR 2.32, 95\% CI 1.10$4.89, \mathrm{p}=0.03)$ and dilated left atrium (HR 1.08, 95\% CI $1.03-1.13, \mathrm{p}=0.002)$. See online supplementary table $\mathrm{S} 1$ (for all online suppl. material, see www.karger.com/ doi/10.1159/000354953).

During a follow-up of $4.2 \pm 2.8$ years (range $0.1-12.2$ years), 57 patients died. Twenty-three deaths (15\%, 23/158), including 8 SCDs, 7 heart failure-related deaths, 7 stroke-related deaths and 1 noncardiovascular death occurred in patients with AF. Thirty-four deaths (7\%, 34/496), including 11 SCDs, 15 heart failure-related 
Table 1. Baseline characteristics of the study population

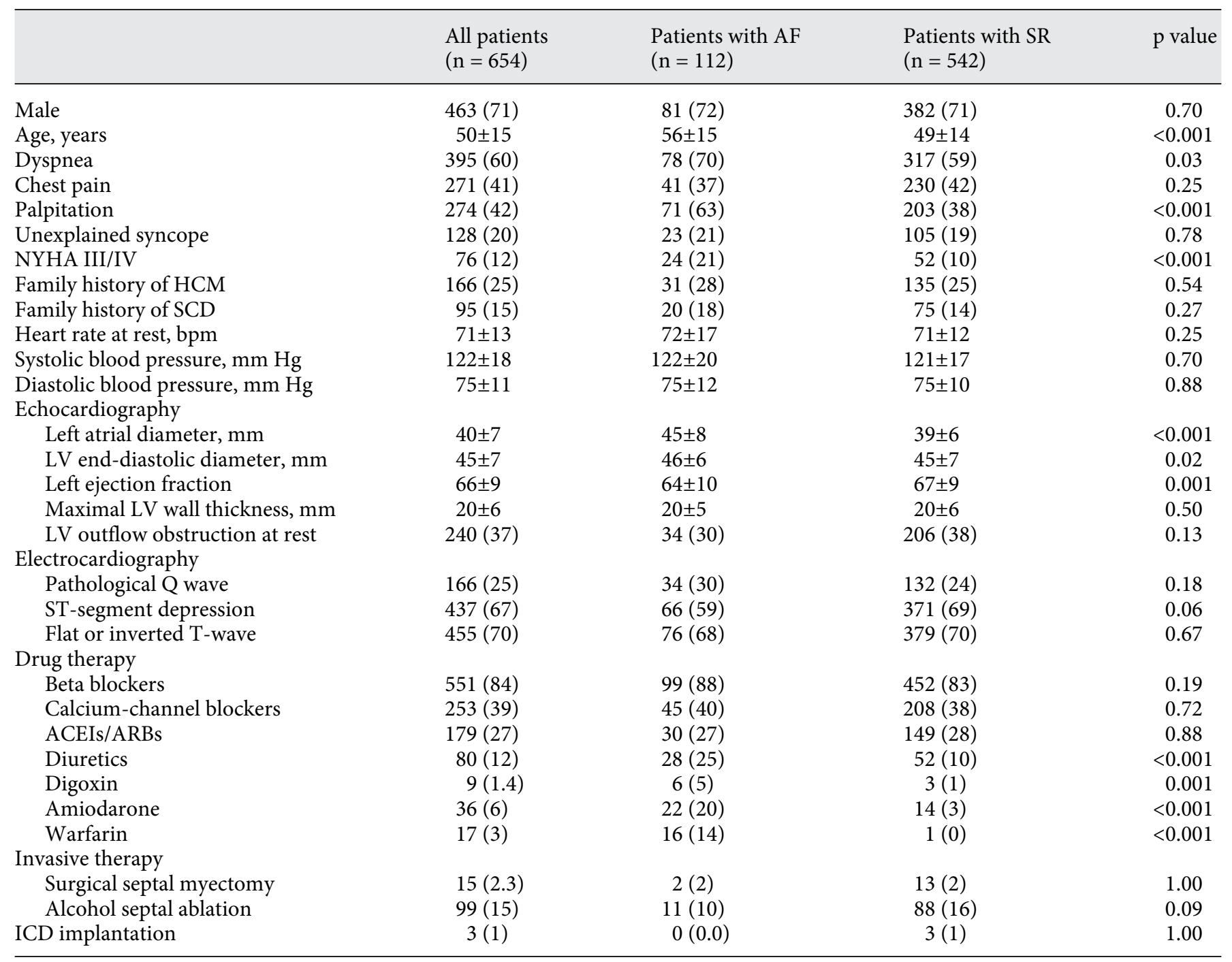

Figures in parentheses are percentages. ACEIs = Angiotensin-converting enzyme inhibitors; ARBs = angiotensin receptor blockers; $\mathrm{SR}=$ sinus rhythm.

deaths, 2 stroke-related deaths and 6 noncardiovascular deaths occurred in the patients with sinus rhythm. The annual incidence of cardiovascular death was $1.8 \%$ in the entire cohort. Kaplan-Meier analysis showed that the patients with AF had a higher risk for all-cause mortality $(\mathrm{p}=0.001)$ and cardiovascular death $(\mathrm{p}<0.001)$ (fig. 1). As for cardiovascular death, the presence of AF was related to an increased risk for SCD $(\mathrm{p}=0.04)$ and strokerelated death $(\mathrm{p}<0.001)$, but not to heart failure-related death $(\mathrm{p}=0.26)$.

Multivariate Cox regression analysis identified AF as an independent risk factor for cardiovascular death (HR
$2.02,95 \%$ CI 1.10-3.70, $\mathrm{p}=0.02)$ and stroke-related death (HR 11.21, 95\% CI 2.22-56.65, p = 0.003) after adjustment for age, gender, unexplained syncope, NYHA function class (III/IV vs. I/II), maximal LV wall thickness, LV outflow tract obstruction (gradient $\geq 30 \mathrm{~mm} \mathrm{Hg}$ ) at rest, LV end-diastolic diameter and a family history of SCD (online suppl. table S2). However, AF was just an independent predictor for stroke-related death (HR 6.71, 95\% CI $1.23-38.58, \mathrm{p}=0.03$ ) after left atrial diameter was included in the multivariate analysis. Conversely, dilated left atrial diameter was significantly associated with allcause death (HR 1.09, 95\% CI 1.05-1.13, p < 0.001) and 
Table 2. Multivariate Cox proportional hazards models for the end points of death

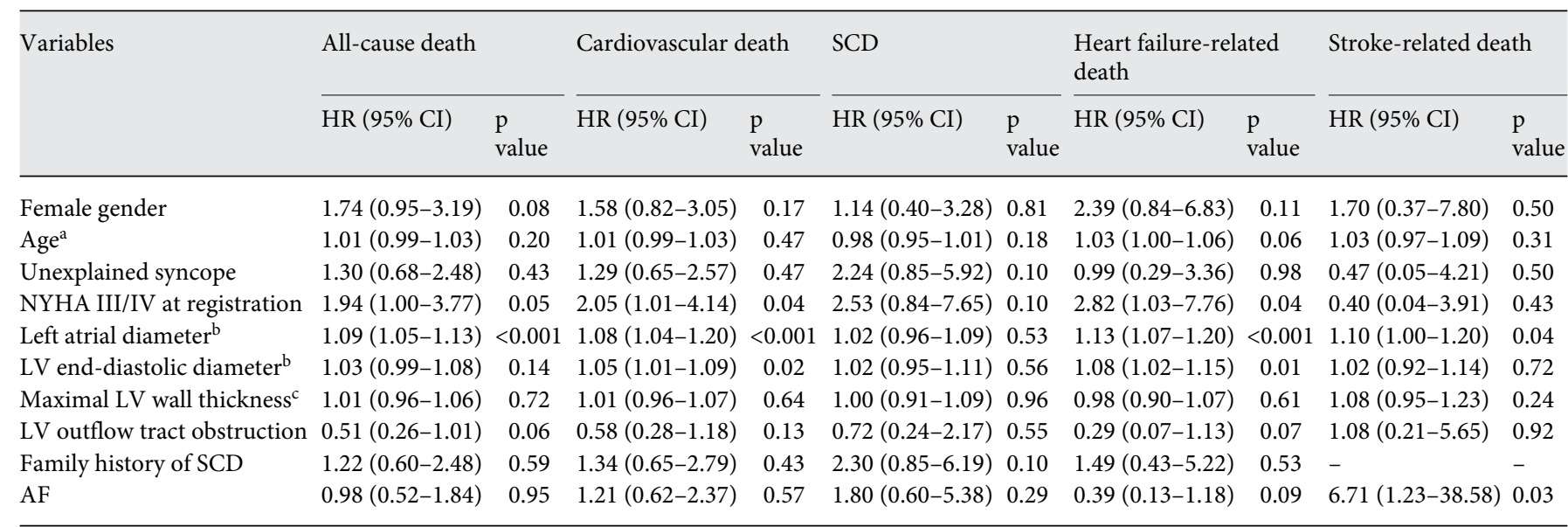

${ }^{a}$ Each 1 -year increase in age. ${ }^{b}$ Each $1-\mathrm{mm}$ increase in diameter. ${ }^{\mathrm{c}}$ Each1-mm increase in wall thickness.

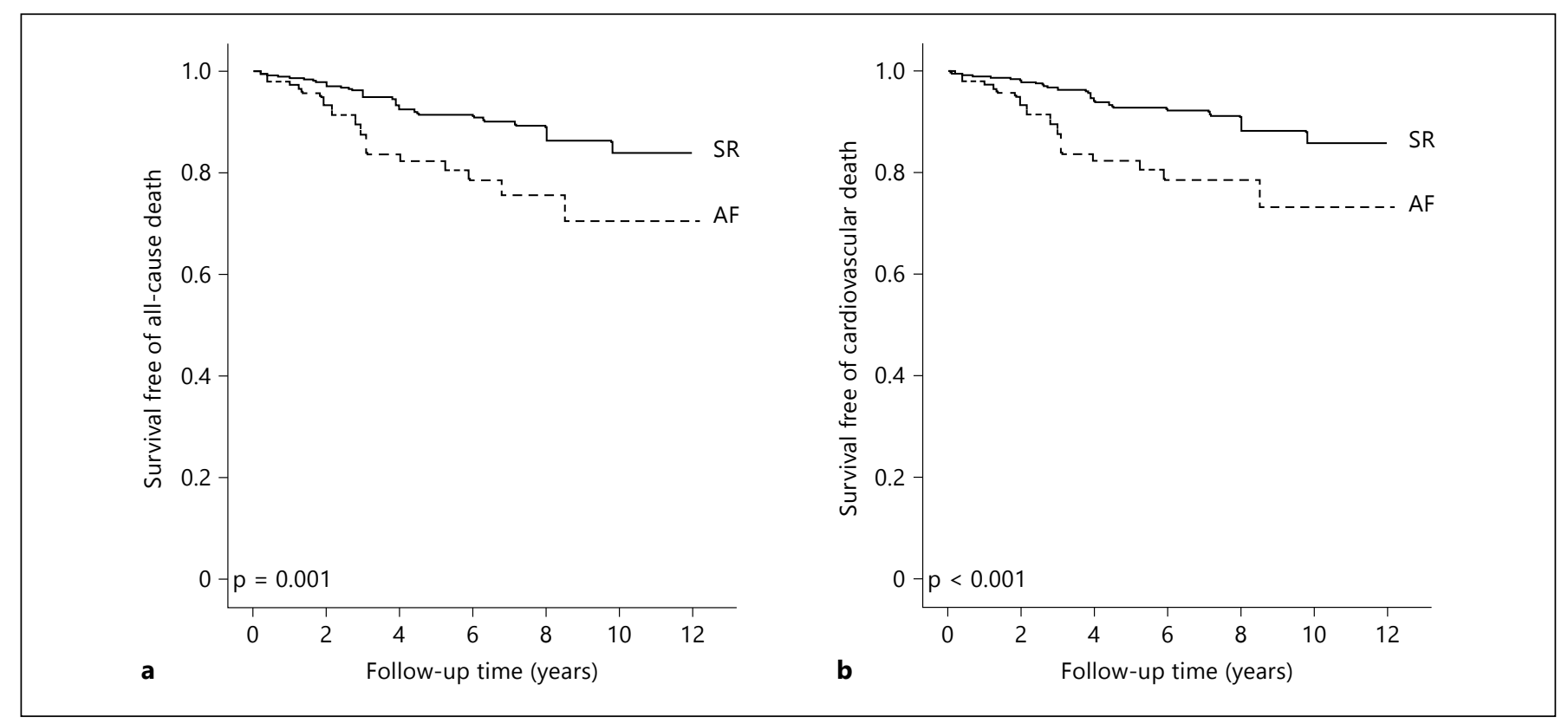

Fig. 1. AF contributed to a higher risk for all-cause death (a) and cardiovascular death (b) than did sinus rhythm (SR).

cardiovascular death (HR 1.08, 95\% CI 1.04-1.20, p < 0.001) (table 2).

The association of AF with the development of advanced chronic heart failure was analyzed in 549 patients after exclusion of patients with a history of NYHA functional class III/IV at enrollment. Kaplan-Meier analysis showed that patients with AF had a higher risk of advanced heart failure $(p<0.001)$ (fig. $2 a)$. Multivariate analysis recognized both AF (HR 1.83, 95\% CI 1.04-3.22, $\mathrm{p}=0.04)$ and left atrial diameter (HR 1.05, 95\% CI 1.01$1.10, p=0.01$ ) to be predictors for this event (online suppl. table S1).

The relationship between AF and the occurrence of ischemic stroke was analyzed in 640 patients after eliminating those with a history of ischemic stroke at enrollment. Kaplan-Meier analysis revealed that patients with 

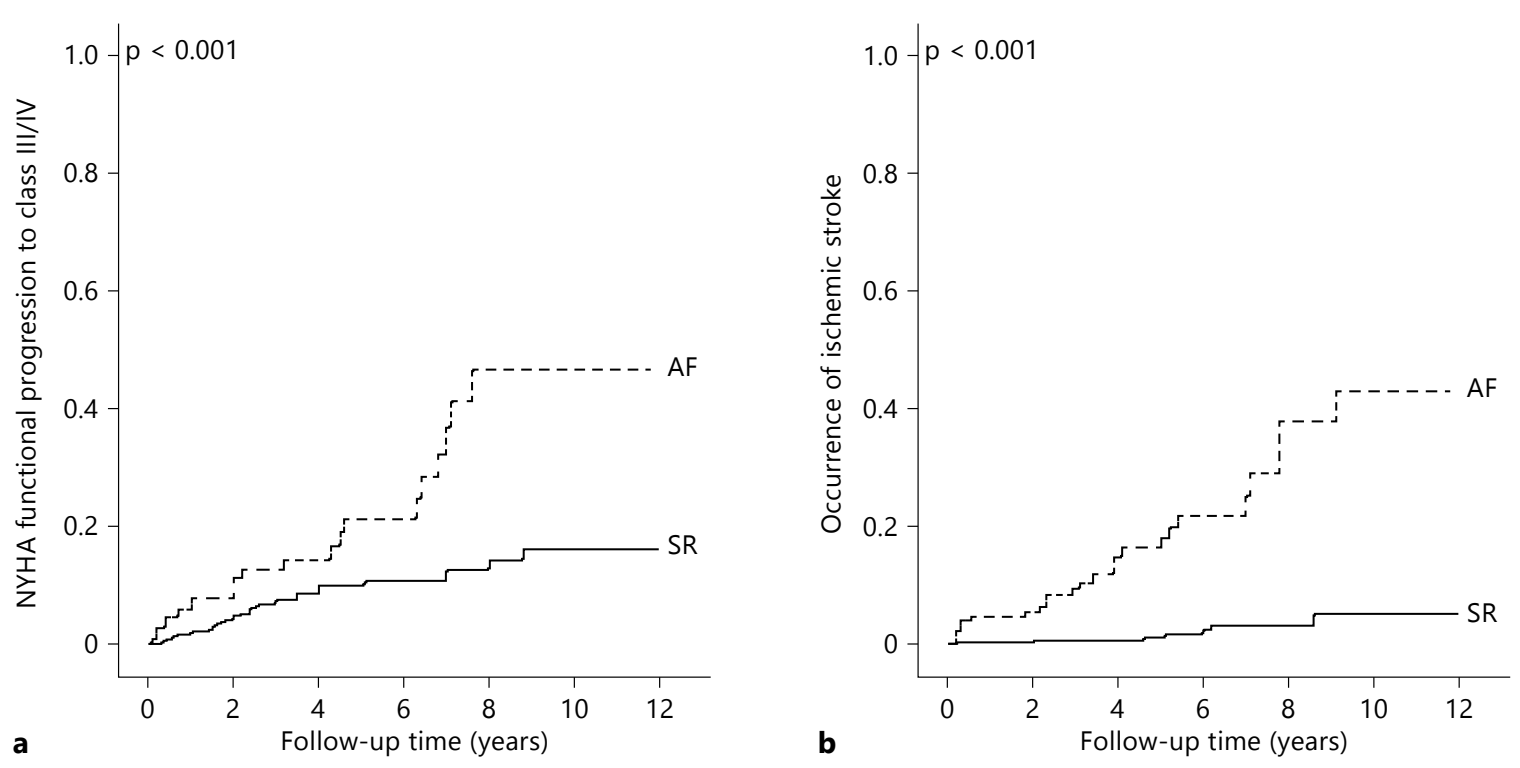

Fig. 2. AF contributed to a higher risk for advanced heart failure (a) and ischemic stroke (b) than did sinus rhythm (SR).

AF were at a higher risk for ischemic stroke than those with sinus rhythm ( $\mathrm{p}<0.001)$ (fig. 2b). Multivariate analysis showed that AF (HR 9.98, 95\% CI 4.06-24.53, p < 0.001 ) and aging (HR 1.03, 95\% CI 1.00-1.06, $\mathrm{p}=0.04$ ) were the independent risk factors for this type of thromboembolic event (online suppl. table S1).

\section{Discussion}

Thus far, research focusing on AF in HCM patients has been sparse and the sample size of most studies is small. Therefore, the prognostic significance of AF in HCM patients needs to be clarified further. In this study, AF was documented in nearly a quarter of 654 unrelated patients in a Chinese HCM cohort. The independent predictors of AF included advancing age, dilated left atrium and severe chronic heart failure. Follow-up study showed that $\mathrm{AF}$ was a predictor for stroke-related death, advanced heart failure and ischemic stroke. Furthermore, a dilated left atrium was also associated with adverse outcomes of HCM and provided additional prognostic information.

In a relatively large study from Olivotto et al. [11], AF was identified in $22 \%(107 / 480)$ of HCM patients. This prevalence was similar to that in our study results (24\%), indicating that $\mathrm{AF}$ is a common complication of $\mathrm{HCM}$.
Furthermore, the authors reported that annual HCM-related mortality was $1.7 \%$ and that AF was related to increased risk for cardiovascular death, advanced heart failure and ischemic stroke. The reported mortality was consistent with our observation of $1.8 \%$, and the associations of AF with advanced heart failure and ischemic stroke were also confirmed in our study. However, we did not find a significant relationship between AF and cardiovascular death. Interestingly, we identified a dilated left atrium as an additional risk factor for cardiac mortality and stroke-related death. If Olivotto et al. [11] did not integrate the size of the left atrium into the multivariate analysis, this could explain why the findings differed. Recently, a small study of $81 \mathrm{HCM}$ patients indicated that AF was not associated with the combined end point of cardiac death or stroke or hospitalization for heart failure when left atrial size was included in a multivariate analysis [18].

Left atrial enlargement has been considered an indicator of the severity of diastolic dysfunction [19]. Some studies have demonstrated a dilated left atrium to be correlated to increased risk for cardiovascular morbidity and mortality in patients with HCM and other forms of cardiac disease [18, 20-23]. Therefore, integrating left atrial diameter into a multivariate analysis may more accurately evaluate the relationship between $\mathrm{AF}$ and prognosis in HCM patients. This hypothesis was confirmed in our 
study: the association of AF with elevated risk for cardiovascular death disappeared after left atrial diameter was integrated into a multivariate analysis. However, a dilated left atrium generated a higher risk for all-cause death and cardiovascular death as well as contributing to the deterioration of chronic heart failure. All these findings suggest that a dilated left atrium should be considered an additional risk factor for adverse prognosis in HCM patients. Consequently, more attention should be focused on patients with left atrial enlargement irrespective of the presence or absence of AF.

At present, the relationship between $\mathrm{AF}$ and SCD in HCM patients is uncertain $[11,24,25]$. In our study, Kaplan-Meier analysis showed that patients with AF were at a higher risk for SCD than those with sinus rhythm, but a multivariate analysis did not support $\mathrm{AF}$ as an independent predictor for this adverse event. Accordingly, the relationship between AF and SCD still needs to be verified in a larger HCM cohort in the future.

Notably, although we highly recommend anticoagulant therapy for the patients with AF who were at high risk for ischemic stroke, only $20 \%$ of patients regularly took anticoagulants. A lack of understanding of the risk of stroke from AF may lead to medication noncompliance, so more effective health education is urgently required for Chinese HCM patients with AF. In addition, our patients prefer medication to invasive therapy and ICD implantation because of concerns about the risks of surgery and for financial reasons. Therefore, some adverse cardiovascular events may be associated with fewer patients adopting these therapies, but the results obtained from this kind of cohort accurately reflect the natural disease course.

Several limitations of this study should be mentioned. First, the subjects in this study were enrolled from a single center. Fuwai Hospital is, however, one of the largest cardiovascular referral hospitals in China, so subjects were representative of a large geographical area. Second, because some patients with AF did not know whether the AF was paroxysmal or persistent during follow-up, they were placed in one AF category without subdividing it. Third, we were unable to explore the influences of duration of AF and degree of rate control on left atrial dilatation and mortality because some patients could not provide detailed information about these factors. In addition, because not all patients in our study were subjected to Holter monitor evaluation (or prolonged monitoring), it may be that we failed to detect some of the asymptomatic, paroxysmal AF cases.

In conclusion, our study demonstrates that $\mathrm{AF}$ is a common complication of HCM and predicts poor outcomes in HCM patients. More attention should be focused on patients with left atrial dilatation because of its impact on the adverse prognosis of HCM.

\section{Acknowledgments}

The authors thank all patients for participating in this study. This work was funded by the Ministry of Science and Technology of China (grant Nos. 2009DFB30050 and 2010CB732601) and the National Natural Science Foundation of China (grant No. 30971233).

\section{References}

$>1$ Maron BJ, Towbin JA, Thiene G, Antzelevitch C, Corrado D, Arnett D, Moss AJ, Seidman CE, Young JB: Contemporary definitions and classification of the cardiomyopathies: an American Heart Association scientific statement from the Council on Clinical Cardiology, Heart Failure and Transplantation Committee, Quality of Care and Outcomes research and Functional Genomics and Translational Biology interdisciplinary working groups and Council on Epidemiology and Prevention. Circulation 2006;113: 1807-1816.

-2 Elliott $\mathrm{P}$, Andersson B, Arbustini E, Bilinska Z, Cecchi F, Charron P, Dubourg O, Kuhl U, Maisch B, McKenna WJ, Monserrat L, Pankuweit S, Rapezzi C, Seferovic P, Tavazzi L, Keren A: Classification of the cardiomyopathies: a position statement from the European Society of Cardiology Working Group on
Myocardial and Pericardial Diseases. Eur Heart J 2008;29:270-276.

-3 Cannan CR, Reeder GS, Bailey KR, Melton LJ 3rd, Gersh BJ: Natural history of hypertrophic cardiomyopathy. A population-based study, 1976 through 1990. Circulation 1995;92: 2488-2495.

4 Cecchi F, Olivotto I, Montereggi A, Santoro G, Dolara A, Maron BJ: Hypertrophic cardiomyopathy in Tuscany: clinical course and outcome in an unselected regional population. J Am Coll Cardiol 1995;26:15291536.

$\checkmark 5$ Harris KM, Spirito P, Maron MS, Zenovich AG, Formisano F, Lesser JR, Mackey-Bojack S, Manning WJ, Udelson JE, Maron BJ: Prevalence, clinical profile, and significance of left ventricular remodeling in the end-stage phase of hypertrophic cardiomyopathy. Circulation 2006;114:216-225.
6 Maron MS, Olivotto I, Betocchi S, Casey SA, Lesser JR, Losi MA, Cecchi F, Maron BJ: Effect of left ventricular outflow tract obstruction on clinical outcome in hypertrophic cardiomyopathy. N Engl J Med 2003;348:295-303.

7 Elliott PM, Gimeno Blanes JR, Mahon NG, Poloniecki JD, McKenna WJ: Relation between severity of left-ventricular hypertrophy and prognosis in patients with hypertrophic cardiomyopathy. Lancet 2001;357:420-424.

-8 Gersh BJ, Maron BJ, Bonow RO, Dearani JA, Fifer MA, Link MS, Naidu SS, Nishimura RA, Ommen SR, Rakowski H, Seidman CE, Towbin JA, Udelson JE, Yancy CW: 2011 ACCF/ AHA guideline for the diagnosis and treatment of hypertrophic cardiomyopathy. Executive summary: a report of the American College of Cardiology Foundation/American Heart Association Task Force on Practice Guidelines. Circulation 2011;124:2761-2796. 
9 Go AS, Hylek EM, Phillips KA, Chang Y, Henault LE, Selby JV, Singer DE: Prevalence of diagnosed atrial fibrillation in adults: national implications for rhythm management and stroke prevention. The Anticoagulation and Risk Factors in Atrial Fibrillation (atria) study. JAMA 2001;285:2370-2375.

10 Maron BJ, Olivotto I, Bellone P, Conte MR, Cecchi F, Flygenring BP, Casey SA, Gohman TE, Bongioanni S, Spirito P: Clinical profile of stroke in 900 patients with hypertrophic cardiomyopathy. J Am Coll Cardiol 2002;39: 301-307.

11 Olivotto I, Cecchi F, Casey SA, Dolara A, Traverse JH, Maron BJ: Impact of atrial fibrillation on the clinical course of hypertrophic cardiomyopathy. Circulation 2001;104:25172524.

-12 Nistri S, Olivotto I, Betocchi S, Losi MA, Valsecchi G, Pinamonti B, Conte MR, Casazza F, Galderisi M, Maron BJ, Cecchi F: Prognostic significance of left atrial size in patients with hypertrophic cardiomyopathy (from the Italian registry for hypertrophic cardiomyopathy). Am J Cardiol 2006;98:960-965.

13 Tani T, Yagi T, Kitai T, Kim K, Nakamura H, Konda T, Fujii Y, Kawai J, Kobori A, Ehara N, Kinoshita M, Kaji S, Yamamuro A, Morioka S, Kita T, Furukawa Y: Left atrial volume predicts adverse cardiac and cerebrovascular events in patients with hypertrophic cardiomyopathy. Cardiovasc Ultrasound 2011;9:34.

-14 Grigioni F, Avierinos JF, Ling LH, Scott CG, Bailey KR, Tajik AJ, Frye RL, Enriquez-Sarano $M$ : Atrial fibrillation complicating the course of degenerative mitral regurgitation: determinants and long-term outcome. J Am Coll Cardiol 2002;40:84-92.
15 Bouchardy J, Therrien J, Pilote L, Ionescu-Ittu R, Martucci G, Bottega N, Marelli AJ: Atrial arrhythmias in adults with congenital heart disease. Circulation 2009;120:1679-1686.

16 Maron BJ, McKenna WJ, Danielson GK, Kappenberger LJ, Kuhn HJ, Seidman CE, Shah PM, Spencer WH 3rd, Spirito P, Ten Cate FJ, Wigle ED: American College of Cardiology/ European Society of Cardiology clinical expert consensus document on hypertrophic cardiomyopathy. A report of the American College of Cardiology Foundation Task Force on clinical expert consensus documents and the European Society of Cardiology committee for practice guidelines. J Am Coll Cardiol 2003;42:1687-1713.

17 Dickstein K, Cohen-Solal A, Filippatos G, McMurray JJ, Ponikowski P, Poole-Wilson PA, Stromberg A, van Veldhuisen DJ, Atar D, Hoes AW, Keren A, Mebazaa A, Nieminen M, Priori SG, Swedberg K: ESC guidelines for the diagnosis and treatment of acute and chronic heart failure 2008: the Task Force for the Diagnosis and Treatment of Acute and Chronic Heart Failure 2008 of the European Society of Cardiology. Developed in collaboration with the Heart Failure Association of the ESC (HFA) and endorsed by the European Society of Intensive Care Medicine (ESICM). Eur J Heart Fail 2008;10:933-989.

18 Yang WI, Shim CY, Kim YJ, Kim SA, Rhee SJ, Choi EY, Choi D, Jang Y, Chung N, Cho SY, Ha JW: Left atrial volume index: a predictor of adverse outcome in patients with hypertrophic cardiomyopathy. J Am Soc Echocardiogr 2009;22:1338-1343.
19 Pritchett AM, Mahoney DW, Jacobsen SJ, Rodeheffer RJ, Karon BL, Redfield MM: Diastolic dysfunction and left atrial volume: a population-based study. J Am Coll Cardiol 2005; 45:87-92.

20 Losi MA, Betocchi S, Barbati G, Parisi V, Tocchetti CG, Pastore F, Migliore T, Contaldi C, Caputi A, Romano R, Chiariello M: Prognostic significance of left atrial volume dilatation in patients with hypertrophic cardiomyopathy. J Am Soc Echocardiogr 2009;22:76-81.

$21 \mathrm{Kim} \mathrm{H}$, Cho YK, Jun DH, Nam CW, Han SW, Hur SH, Kim YN, Kim KB: Prognostic implications of the NT-ProBNP level and left atrial size in non-ischemic dilated cardiomyopathy. Circ J 2008;72:1658-1665.

22 Ristow B, Ali S, Whooley MA, Schiller NB: Usefulness of left atrial volume index to predict heart failure hospitalization and mortality in ambulatory patients with coronary heart disease and comparison to left ventricular ejection fraction (from the Heart and Soul study). Am J Cardiol 2008;102:70-76.

23 Le Tourneau T, Messika-Zeitoun D, Russo A Detaint D, Topilsky Y, Mahoney DW, Suri R, Enriquez-Sarano M: Impact of left atrial volume on clinical outcome in organic mitral regurgitation. J Am Coll Cardiol 2010;56:570578.

24 Sorajja P, Ommen SR, Nishimura RA, Gersh BJ, Berger PB, Tajik AJ: Adverse prognosis of patients with hypertrophic cardiomyopathy who have epicardial coronary artery disease. Circulation 2003;108:2342-2348.

25 Pacileo G, Salerno G, Gravino R, Calabro R, Elliott PM: Risk stratification in hypertrophic cardiomyopathy: time for renewal? J Cardiovasc Med (Hagerstown) 2013;14:319-325. 